\title{
La exasperación de la pena en el concurso material de delitos: la reiteración de delitos de la misma especie
}

\author{
Guillermo Oliver Calderón*
}

\section{RESUMEN}

En el presente trabajo se examinan varios problemas interpretativos que se han originado con motivo de la aplicación de la regla de penalidad de la reiteración de delitos de la misma especie, del artículo 351 del Código Procesal Penal, y se sugiere cómo deben solucionarse. Además, se analizan algunos casos de reiteración de delitos de la misma especie que se encuentran sometidos a reglas especiales.

Concurso material de delitos - reiteración de delitos de la misma especie

- exasperación de la pena

\section{Aggravation of the punishment in cases of concurrent offences: the repetition of offenses of the same kind}

\begin{abstract}
This paper analyzes several interpretive problems that have arisen with regard to the application of the rule of repetition of offenses of the same kind, of Article 351 of the Chilean Criminal Procedure Code, and suggests how they must be solved. It also analyzes some cases of repeated offenses of the same kind that are subjected to special rules.
\end{abstract}

Concurrent offences - repetition of offenses of the same kind - aggravation of punishment

* Abogado, Doctor en Derecho, Profesor de Derecho Penal y Derecho Procesal Penal en la Pontificia Universidad Católica de Valparaíso, Chile. Correo electrónico: guillermo.oliver@ucv.cl.

El autor agradece a don Pablo Aravena Santibáñez y a doña Carmen Calderón Ortiz, ayudantes del Departamento de Derecho Penal y Derecho Procesal Penal de la Pontificia Universidad Católica de Valparaíso, por su colaboración, respectivamente, en el proceso de edición de este trabajo y en la búsqueda de jurisprudencia pertinente.

Artículo recibido el 30 de agosto de 2013 y aceptado para su publicación por el Comité Editorial el 28 de octubre de 2013. 


\section{INTRODUCCIÓN}

$\mathrm{S}$

e conoce con el nombre exasperación una regla de determinación de penas de los concursos de delitos propia del sistema de acumulación jurídica, que conduce a la imposición de una sanción más severa que la correspondiente al delito más grave, pero inferior a la suma de las penas de todos los cometidos. Concretamente, con dicha denominación se alude al mecanismo consistente en agravar la sanción asignada a la figura más grave, por ejemplo, imponiendo la pena superior en un grado.

La exasperación se diferencia de la absorción en que mientras en esta la pena a imponer no puede exceder del marco de la pena base (la del delito más grave), en aquella debe superarlo ${ }^{1}$. También se distingue de la acumulación, ya que mientras en esta se aplican varias sanciones, en la exasperación se impone solo una, de lo que se desprende la importante consecuencia de que las penas accesorias que en este último sistema cabe aplicar son exclusivamente las correspondientes a la única pena principal definitivamente impuesta ${ }^{2}$.

Probablemente, la hipótesis más conocida de exasperación en el ordenamiento jurídico chileno es la de la reiteración de delitos de la misma especie, prevista en el artículo 351 del Código Procesal Penal, como en los casos de reiteración de crímenes o simples delitos de una misma especie se impondrá la pena correspondiente a las diversas infracciones, estimadas como un solo delito, aumentándola en uno o dos grados (primer inciso). En su segundo inciso, la disposición agrega que si, por la naturaleza de las diversas infracciones, estas no pudieren estimarse como un solo delito, el tribunal aplicará la pena señalada a aquella que, considerada aisladamente, con las circunstancias del caso, tuviere asignada una pena mayor, aumentándola en uno o dos grados, según fuere el número de los delitos. En su tercer inciso, el precepto añade que podrá, con todo, aplicarse las penas en la forma establecida en el artículo 74 del Código Penal si, de seguirse este procedimiento, hubiere de corresponder al condenado una pena menor. Finaliza la disposición señalando que para los efectos de este artículo, se considerará delitos de una misma especie aquellos que afectaren al mismo bien jurídico (inciso cuarto).

El artículo 397 del Código Procesal Penal extiende estas reglas a la reiteración de faltas de una misma especie.

Entiendo la voz "reiteración" como sinónimo de concurso material o real de de$\operatorname{litos}^{3}$. No obstante, hay quienes utilizan dicho vocablo para aludir solo a un concurso material de delitos de la misma especie ${ }^{4}$, proceder que no comparto, porque conduce

${ }^{1}$ Cfr. Sanz, A.J., El concurso de delitos. Aspectos de politica legislativa, Universidad de Valladolid, Valladolid, 1986, p. 31

${ }^{2}$ Así, Cuerda, A., Concurso de delitos y determinación de la pena, Tecnos, Madrid, 1992, p. 98.

${ }^{3}$ En este sentido, Cury, E., Derecho Penal. Parte General, 10 a edición, Ediciones Universidad Católica de Chile, Santiago, 2011, pp. 659-660. Véanse también las sentencias de la Corte Suprema, de 24 de febrero de 2011, dictada en causa rol No 10162-2010, y de 14 de julio de 2008, dictada en causa rol No 2146-2008.

${ }^{4}$ Así, Etcheberry, A., Derecho Penal. Parte General, $3^{\text {a } e d i c i o ́ n, ~ E d i t o r i a l ~ J u r i ́ d i c a ~ d e ~ C h i l e, ~ S a n t i a g o, ~ 1998, ~}$ T. II, p. 116; Labatut, G., Derecho Penal, $9^{a}$ edición, Editorial Jurídica de Chile, Santiago, 2000, T. I, p. 171; Ortiz, L.; Arévalo, J., Las consecuencias jurídicas del delito, Editorial Jurídica de Chile, Santiago, 2013, p. 335. 
a calificar como redundantes todas las referencias que hace la ley a las reiteraciones de delitos de una misma especie ${ }^{5}$.

\section{EvOLUCión HISTÓRICA}

El antecedente histórico inmediato del artículo 351 del Código Procesal Penal es el artículo 509 del aún vigente Código de Procedimiento Penal, precepto casi idéntico a aquel y cuya regulación ha sufrido varios cambios en el tiempo ${ }^{6}$.

Desde la entrada en vigencia del Código Penal (1 de marzo de 1875) y hasta antes de la entrada en vigor del Código de Procedimiento Penal (1 de marzo de 1907), los concursos materiales de delitos se castigaban, en general, según la regla de acumulación aritmética de las penas del artículo 74 del primero de dichos textos legales ( $A l$ culpable de dos o más delitos se le impondrán todas las penas correspondientes a las diversas infracciones). En ocasiones, esto dio lugar a que se aplicaran penas exorbitantes, prácticamente imposibles de cumplir o portadoras de contradicciones valorativas, por superar las penas previstas en la ley para los delitos más graves, lo que motivó la formulación de considerables críticas por parte de la doctrina ${ }^{7}$.

A partir de la entrada en vigencia del Código de Procedimiento Penal y hasta antes de la dictación de la Ley $\mathrm{N}^{\circ} 3.988$, de 20 de octubre de 1923, a las reiteraciones de simples delitos de una misma especie se les aplicó el artículo 537 de tal Código, cuyo tenor era el siguiente: En los casos de reiteración de simples delitos de una misma especie, se impondrá la pena correspondiente a las diversas infracciones, estimadas como un solo delito, aumentándola en uno, dos o tres grados.

La citada Ley $\mathrm{N}^{\circ} 3.988$ hizo extensiva la regla de exasperación a la reiteración de simples delitos de una misma especie que por su naturaleza no pueden estimarse como uno solo, estableció la posibilidad de aplicar la regla de acumulación material del

${ }^{5}$ Cfr. Cortés, J.L., Algunos aspectos de la reiteración de delitos de la misma especie, Seminario de titulación Magíster en Derecho Penal y Ciencias Penales, Pontificia Universidad Católica de Valparaíso, Valparaíso, 2012, p. 2, n. 3.

Por un sentido más amplio del término "reiteración”, que incluiría también los casos de reincidencia, se inclina Mañalich, J.P., “¿Discrecionalidad judicial en la determinación de la pena en caso de concurrencia de circunstancias atenuantes de la responsabilidad penal?”, en Informes en Derecho. Doctrina Procesal Penal 2009, núm. 7, octubre 2010, p. 43, n. 5.

${ }^{6}$ Las referencias a las sucesivas modificaciones experimentadas por el artículo 509 del Código de Procedimiento Penal, que se reseñan en el cuerpo de este trabajo, han sido extraídas de Solari, T., Rodríguez, L., "Determinación de la pena en los casos de reiteración de delitos (ámbito de aplicación del artículo 509 del Código de Procedimiento Penal)”, en Revista de Derecho, Universidad Católica de Valparaíso, vol. III, 1979, pp. 258 -259.

7 Véase Correa, A., "Ochenta y cuatro años de presidio", en Revista Forense Chilena, núm. 4, 1888, pp. 508-511; Feliú, D., "De la acumulación de los delitos según nuestro Código Penal”, en Revista Forense Chilena, núm. 6, 1890, pp. 436-444; Latorre, E. et al., "Ciento veintitrés años cuarenta y un días de presidio", en Revista Forense Chilena, núm. 13, 1899, pp. 399-402. Con especial elocuencia, criticaba el sistema de acumulación aritmética Fuensalida, A., Concordancias y comentarios del Código Penal chileno, Lima, 1883, T. I, p. 321, al afirmar que "esa acumulación [...] puede hacer subir la suma total hasta un grado superior a la vida humana, como si las penas pudiesen recaer sobre animales antediluvianos”. 
artículo 74 del Código Penal en caso de resultar más favorable al reo, amplió el campo de aplicación del precepto a la reiteración de faltas de una misma especie y definió lo que debía entenderse por delitos de la misma especie. Todo ello lo hizo, agregando al mencionado artículo 537 los siguientes cuatro incisos: Si por la naturaleza de las diversas infracciones, estas no pudieren estimarse como un solo delito, el tribunal aplicará la pena señalada a aquella que, considerada aisladamente, con las circunstancias del caso, tenga asignada pena mayor, aumentándola en uno, dos o tres grados, según sea el número de delitos (inciso segundo). Podrán, con todo, aplicarse las penas en la forma establecida en el artículo 74 del Código Penal si, de seguir este procedimiento, bubiere de corresponder al reo una pena menor (inciso tercero). Las reglas anteriores se aplicarán también en los casos de reiteración de una misma falta (inciso cuarto). Para los efectos de este artículo se considerarán delitos de una misma especie aquellos que estén penados en un mismo título del Código Penal o ley que los castiga (inciso quinto).

La Ley $\mathrm{N}^{\circ} 7.836$, de 7 de septiembre de 1944, modificó el texto del citado artículo 537, que pasó a llevar por número el 509, incluyendo a los crímenes dentro del régimen de exasperación que el precepto consagra. Desde entonces y hasta la fecha, el tenor de dicha disposición se ha mantenido inalterado.

Como puede advertirse, el texto del artículo 351 (y del 397) del Código Procesal Penal es prácticamente idéntico al del artículo 509 del Código de Procedimiento Penal, salvo en lo relativo a lo que debe entenderse por delitos de la misma especie y al número de grados de pena en que debe hacerse la exasperación.

\section{Concepto de “Delitos de la misma especie”}

Ciertamente, la explicación legal acerca de lo que se entiende por delitos de la misma especie para efectos del artículo 351 del Código Procesal Penal (aquellos que afectaren al mismo bien jurídico) merece una valoración positiva, ya que resulta mucho más satisfactoria que la que se contenía en su antecedente, el artículo 509 del Código de Procedimiento Penal (aquellos que estén penados en un mismo título del Código Penal o ley que los castiga), la que era muy criticada por la doctrina, ya que conducía a estimar de la misma especie delitos tan disímiles entre sí, como, por ejemplo, el homicidio y la injuria, o el aborto y la violación, y a considerar de distinta especie el infanticidio y el aborto ${ }^{8}$. Pero, de todas formas, la previsión legal genera dudas interpretativas ${ }^{9}$, muy similares a las que produce la agravante de reincidencia específica (artículo $12 \mathrm{~N}^{\circ} 16 \mathrm{CP}$ ).

Es en los estudios de la parte especial del derecho penal donde se explica cuál es el bien jurídico que se ve tutelado en cada uno de los delitos, lo que ya dificulta la aplicación segura del citado artículo 351, especialmente si se considera que hay figuras delictivas respecto de las cuales no existe consenso doctrinal acerca de cuál es el bien jurídico que protegen ${ }^{10}$.

\footnotetext{
${ }^{8}$ Por todos, Cury, E. Derecho Penal. Parte General, p. 661.

${ }^{9}$ Cfr. Ortiz, L.; Arévalo, J., Las consecuencias jurídicas del delito, pp. 335-336.

${ }^{10}$ Solo a título ejemplar, repárese en la discusión existente en torno a la determinación del bien jurídico atacado en el robo por sorpresa. Mientras unos afirman que, además de los intereses meramente patrimoniales,
} 
A ello debe añadirse el problema de determinar si es exigible o no una identidad exacta de bienes jurídicos afectados, ya que hay varios delitos que son pluriofensivos, o sea, que tutelan dos o más bienes jurídicos. En estos casos, la dificultad consiste en establecer si pueden considerarse de la misma especie dos delitos cuando el primero de ellos protege un solo bien jurídico, que también se ve tutelado, junto con otros, en el segundo; o bien, cuando se trata de dos delitos pluriofensivos que tienen en común el hecho de proteger un mismo bien jurídico, dentro de los varios que tutelan ${ }^{11}$.

Según mi opinión, el recurso a la función sistemática de los bienes jurídicos, conforme a la cual el legislador clasifica los distintos delitos dentro del Código Penal ${ }^{12}$, permite sostener que no es necesaria una identidad exacta de bienes jurídicos afectados para considerar dos o más delitos como pertenecientes a una misma especie. Téngase en cuenta que la anterior definición de delitos de la misma especie se basaba, precisamente, en un criterio sistemático y que no era criticada por ello, sino por las indeseables consecuencias que en ocasiones producía el modo excesivamente formal en que estaba consagrado. Atender a la función sistemática de los bienes jurídicos serviría entonces para "rescatar" el aspecto útil de la regulación anterior ${ }^{13}$. Debido a esta función el legislador podría agrupar conjuntamente diversos delitos, aunque sus bienes jurídicos coincidieran solo parcialmente, nada impide aplicar la regla de determinación de pena de la reiteración de delitos de la misma especie a hipótesis de varios delitos pluriofensivos. Lo único que se requiere es que en todos los delitos concurrentes exista, al menos, un mismo bien jurídico común ${ }^{14}$.

A estas consideraciones debe agregarse el hecho de que, en materia de reincidencia específica, hay quienes exigen, para aplicar esta circunstancia, además de que se afecte el mismo bien jurídico, que se repita la misma forma de atentado en su contra ${ }^{15}$, y

se produce un atentado contra la integridad física de la víctima, que se ve expuesta a un peligro (así, Politoff, S.; Matus, J.P.; Ramírez, M.C., Lecciones de Derecho Penal chileno. Parte Especial, $2^{a}$ edición, Editorial Jurídica de Chile, Santiago, 2004, pp. 375-376), otros sostienen que no se ve afectado ningún bien jurídico distinto del puramente patrimonial (en este sentido, Mera, J., Hurto y robo, LexisNexis, Santiago, 1995, pp. 96-97). Sobre el tema, con detalle, véase Oliver, G., Delitos contra la propiedad, Thomson Reuters LegalPublishing, Santiago, 2013, pp. 378-382.

${ }^{11}$ Se inclina por la repuesta afirmativa Matus, J.P., "Proposiciones respecto de las cuestiones no resueltas por la Ley $\mathrm{N}^{\circ} 20.084$ en materia de acumulación y orden de cumplimiento de las penas", en Ius et Praxis, núm. 2, 2008, p. 535. Por su parte, Bustos, J.; Hormazábal, H., Lecciones de Derecho Penal Chileno, adaptadas por José Ángel Fernández Cruz, vol. I, Librotecnia, Santiago, 2012, p. 250, proponen atender, en los casos de delitos pluriofensivos, al bien jurídico que represente el núcleo central de la desvaloración penal.

12 Por todos, Mir, S., Derecho Penal. Parte General, $7^{\mathrm{a}}$ edición, B de F, Montevideo - Buenos Aires, 2004 , p. 169.

${ }^{13}$ Cfr. Cortés, J.L., Algunos aspectos de la reiteración de delitos de la misma especie, pp. 8-10.

${ }^{14}$ Por estas razones, he modificado la postura que, implícitamente, asumí en Oliver G., Delitos contra la propiedad, pp. 278 y 378, al afirmar, respectivamente, que un hurto y un robo con violencia o intimidación en las personas no son delitos de la misma especie para efectos del artículo 351 del Código Procesal Penal, y que tampoco lo son dicha clase de robo y un robo por sorpresa.

15 Así, Cury, E. Derecho Penal. Parte General, p. 512. 
algunos requieren, adicionalmente, que haya identidad de móviles en el autor ${ }^{16}$, lo que sería relevante si se pretendiera extraer de la regulación de dicha agravante un criterio para la interpretación de la regla de punición de la reiteración de delitos de la misma especie. No obstante, no parece razonable extender estos planteamientos, formulados en la determinación del ámbito de aplicación de una agravante, a la regla del artículo 351 del Código Procesal Penal, que ha sido creada para permitir un tratamiento punitivo más benigno que el de la acumulación aritmética de las penas.

En cualquier caso, frente a todas estas dudas, en principio, parece preferible efectuar una interpretación extensiva del ámbito de aplicación de la mencionada regla, es decir, no ser demasiado exigente en la constatación de la concurrencia de sus requisitos, ya que siempre será posible aplicar la regla general de punición del concurso material de delitos (Art. $74 \mathrm{CP}$ ) si ello resulta más favorable para el imputado (Art. 351 inc. $\left.3^{\circ} \mathrm{CPP}\right)^{17}$.

\section{Posibilidad De ESTIMAR VARIAS INFRACCIONES COMO UN SOLO DELITO}

Cuando existe una reiteración de delitos de la misma especie, es necesario determinar si las diversas infracciones pueden ser estimadas o no como un solo delito, ya que de ello depende el camino a seguir: en caso afirmativo, se debe aplicar el inciso primero del citado artículo 351; en caso contrario, el inciso segundo ${ }^{18}$. Según lo que señala la doctrina mayoritaria, el criterio que se debe utilizar para aplicar esta distinción consiste en examinar si las penas de los distintos delitos se encuentran estructuradas o no sobre bases acumulables que se puedan sumar: si así fuera, como ocurre, por ejemplo, en los hurtos, las estafas y los daños, se aplicaría el inciso primero; si no fuera así, se aplicaría el inciso segundo ${ }^{19}$. En la jurisprudencia es posible encontrar varios fallos en este sentido ${ }^{20}$.

\footnotetext{
${ }^{16}$ En este sentido, Novoa, E., Curso de Derecho Penal Chileno. Parte General, 3 a edición, Editorial Jurídica de Chile, Santiago, 2005, T. II, pp. 84-85.

${ }^{17}$ Bullemore, V.; Mackinnon, J., Curso de Derecho Penal, Teoría del delito, LexisNexis, Santiago, 2007, T. II, p. 212: "Debemos [...] considerar el texto legal como un punto de partida, que ha de interpretarse en beneficio del reo".

${ }^{18}$ Véase Oliver, G., “Aproximación a la unificación de penas”, en Política Criminal, vol. 7, núm. 14, diciembre 2012, pp. 266-267.

${ }^{19}$ Cfr. Politoff, S.; Matus J.P.; Ramírez, M.C., Lecciones de Derecho Penal Chileno. Parte General, $2^{\mathrm{a}}$ edición, Editorial Jurídica de Chile, Santiago, 2004, p. 467. También Novoa, E., Curso de Derecho Penal Chileno. Parte General, T. II, p. 227, aunque refiriéndose al artículo 509 del Código de Procedimiento Penal. Implícitamente, Etcheberry, Derecho Penal. Parte General, T. II, p. 117.

Por otra parte, una antigua opinión doctrinal sostenía que la referencia legal a la estimación de diversas infracciones como un solo delito era una alusión al delito continuado. Así, Ortiz, P., Curso breve de Derecho Penal (común y militar), Imprenta de Carabineros de Chile, Santiago, 1947, p. 202, aunque examinando el artículo 509 del Código de Procedimiento Penal. Entre otras razones, esta idea ha sido abandonada, porque, como lo veremos someramente más adelante, la doctrina entiende que la consecuencia de apreciar un delito continuado es imponer la pena correspondiente al único hecho cometido, lo que se opone a la exasperación punitiva ordenada por la ley.

${ }^{20}$ Entre muchas otras sentencias, pueden verse las de la Corte Suprema, de 18 de abril de 2000, dictada en causa rol $\mathrm{N}^{\circ} 301-2000$, y de la Corte de Apelaciones de Santiago, de 8 de enero de 2010, dictada en causa rol No3312-2009, y de 9 de julio de 2001, dictada en causa rol No 37936-2001.
} 
Según mi opinión, este criterio no resulta aceptable por varias razones ${ }^{21}$. Por una parte, porque implica vulnerar el principio non bis in idem, al considerar en dos ocasiones un mismo hecho en un sentido perjudicial para el imputado. En efecto, esta interpretación obliga, cuando se trata, por ejemplo, de varios delitos de hurto, a tomar en cuenta todas las infracciones para determinar un marco penal (al sumar las cuantías involucradas en cada uno de los delitos, inevitablemente se está considerando la totalidad de las infracciones), y luego, nuevamente, el número de los delitos concurrentes para precisar el número de grados en que se aumentará la pena ${ }^{22}$. Es cierto que la alusión al "número de los delitos" aparece explícitamente solo en el inciso segundo del mencionado artículo 351, pero es evidente que dicho criterio para determinar el aumento de grados está implícito también en el inciso primero ${ }^{23}$.

Por otra parte, como consecuencia de lo anterior, esta interpretación conduce a una injustificable diferencia de trato para el imputado, según se aplique el primer o el segundo inciso del artículo 351. El primer inciso supondría un tratamiento mucho más severo que el segundo, ya que en este último, al tomar el legislador como base el delito que tenga asignada una pena mayor, simplemente se prescinde de las restantes infracciones, estimando el aumento de grado como suficiente compensación por este hecho. No existen motivos para sostener que la situación recogida en el primer inciso sea más grave que la contemplada en el segundo y así explicar esta diferencia ${ }^{24}$.

Además, el planteamiento que critico comporta una aplicación analógica perjudicial para el imputado, de lo prescrito en el artículo 451 del Código Penal (disposición que examino más adelante y que alude expresamente a la suma de cuantías de diversos

${ }^{21}$ Por los motivos que expongo a continuación en este trabajo, he modificado el punto de vista asumido en Rodríguez, L.; Oliver, G., "Aplicabilidad de la figura del delito continuado en los delitos sexuales. Comentario a un fallo", en Revista de Derecho, Universidad Católica del Norte, núm. 1, año 16, 2009, p. 260.

22 En este sentido, Couso, J., "Comentario previo a los arts. 74 y 75”, en Couso, J.; Hernández, H. (dirs.), Código Penal Comentado. Parte General. Doctrina y Jurisprudencia, Abeledo Perrot LegalPublishing Chile, Santiago, 2011, pp. 650-651; Solari, T.; Rodríguez, L., "Determinación de la pena en los casos de reiteración de delitos (ámbito de aplicación del artículo 509 del Código de Procedimiento Penal)”, p. 267.

${ }^{23}$ Así, Novoa, E., Curso de Derecho Penal Chileno. Parte General, T. II, p. 227, n. 9, aunque haciendo referencia al artículo 509 del Código de Procedimiento Penal. En el mismo sentido, Couso, J., "Comentario previo a los artículos 74 y 75”, p. 652. Véase también Muñoz, H., "Contribución al estudio de la teoría de los concursos de delitos", en Revista Chilena de Derecho, Pontificia Universidad Católica de Chile, vol. 13, núm. 2, 1986, p. 349, quien aludiendo al citado artículo 509, propone para determinar el número de grados en que se aumente la pena, además del número de delitos, atender a la entidad de estos, criterio que dicha disposición no menciona, al igual que el artículo 351 del Código Procesal Penal. Por su parte, Ortiz, L.; Arévalo, J., Las consecuencias jurídicas del delito, p. 340, se inclinan por "un sistema de aumento de penalidad bajo un criterio valorativo amparado en la culpabilidad y por el injusto, criterio que permitiría al sentenciador, excluyendo parámetros meramente aritméticos, buscar la pena que más se avenga con la totalidad de los ilícitos cometidos por el delincuente".

${ }^{24}$ Solari, T.; Rodríguez, L., "Determinación de la pena en los casos de reiteración de delitos (ámbito de aplicación del art. 509 del Código de Procedimiento Penal)”, p. 266. 
delitos de hurto), porque lleva a la imposición de una pena mayor que la que resultaría de aplicar el inciso segundo del citado artículo $351^{25}$.

Podría argüirse a favor de la tesis que impugno el hecho de que ella parece corresponder a la voluntad de los redactores de la ley. En efecto, en el acta de la sesión $\mathrm{N}^{\mathrm{o}} 21$ de la Comisión Mixta de Senadores y Diputados encargada de revisar el Proyecto de Código de Procedimiento Penal, a propósito del artículo 537 (que rezaba así: En los casos de reiteración de simples delitos de una misma especie, se impondrá la pena correspondiente a las diversas infracciones, estimadas como un solo delito, aumentándola en uno, dos o tres grados), que tiempo después se convirtió en el artículo 509, se dejó constancia de la siguiente intervención del señor Valdés: "Cuando se trata de la reiteración de este delito [hurto], será necesario, para aplicar la disposición en estudio, sumar el valor de los objetos que han sido materia de las diversas infracciones y esta suma será la cantidad que debe tomarse en cuenta para aplicar la pena en la forma que ella determina". "La Comisión aceptó unánimemente la interpretación [...] del señor Valdés y en esta inteligencia mantuvo el artículo del Proyecto" ${ }^{26}$. Sin embargo, hace tiempo ya que se ha aceptado la idea de que todo proceso interpretativo ha de estar encaminado a determinar más bien la voluntad de la ley en el presente (teoría objetiva de la interpretación) y no tanto la que tenía a la época de su dictación o la que albergaban sus redactores (teoría subjetiva de la interpretación ${ }^{27}$. Además, no puede dejar de considerarse que la voluntad de los miembros de aquella comisión se manifestó respecto de una ley distinta del Código Procesal Penal (¡dictada un siglo antes!) y de un precepto de contenido diferente al del artículo $351 \mathrm{CPP}$, por lo que no resulta decisiva ${ }^{28}$.

Por último, no parece razonable tener en cuenta la forma como están establecidas las penas de las diversas infracciones para estimarlas o no como un solo delito, ya que la ley expresamente indica que para hacer esta consideración debe atenderse a "la naturaleza de las diversas infracciones" (artículo 351 inc. $2^{\circ} \mathrm{CPP}$ ). Es evidente que no forma parte de la naturaleza de un delito el criterio que utiliza el legislador para sancionarlo, como, por ejemplo, la cuantificación de su objeto material ${ }^{29}$.

${ }^{25}$ Así, Garrido, M., Derecho Penal. Parte general, $2^{a}$ edición, Editorial Jurídica de Chile, Santiago, 2001, T. II, p. 346, n. 687; Matus, J.P., "Proposiciones respecto de las cuestiones no resueltas por la Ley N 20.084 en materia de acumulación y orden de cumplimiento de las penas”, p. 536.

${ }^{26}$ Lazo, S., Código de Procedimiento Penal. Orígenes, concordancias, jurisprudencia, Poblete Cruzat Hnos. Editores, Santiago, 1916, p. 364.

${ }^{27}$ Así, Cury, E., Derecho Penal. Parte General, pp. 187-190. Reconoce que la teoría objetiva es la dominante Jescheck, H., Tratado de Derecho Penal. Parte General, traducción de la $4^{\text {a }}$ edición alemana de José Luis Manzanares Samaniego, Comares, Granada, 1993, pp. 139-140. Véase también Roxin, C., Derecho Penal. Parte General, traducción de la $2^{a}$ edición alemana de Diego-Manuel Luzón Peña, Miguel Díaz y García Conlledo y Javier de Vicente Remesal, Civitas, Madrid, 1997, T. I, pp. 150-151, quien se inclina, más bien, por un planteamiento intermedio en el que, en todo caso, predominan las consideraciones objetivas.

${ }^{28}$ Couso, J., “Comentario previo a los artículos 74 y 75”, p. 650.

${ }^{29}$ En este sentido, Solari, T.; Rodríguez, L., "Determinación de la pena en los casos de reiteración de delitos (ámbito de aplicación del artículo 509 del Código de Procedimiento Penal)”, p. 263. 
A mi juicio, entonces, el criterio de distinción consiste, simplemente, en examinar si los varios delitos de la misma especie configuran una reiteración de un mismo delito o de delitos distintos ${ }^{30}$. En el primer caso habrá que aplicar el inciso primero del artículo 351; en el segundo caso, el inciso segundo ${ }^{31}$. De todas formas, por las razones que explicaré enseguida, carece de toda importancia práctica la decisión de aplicar uno u otro inciso.

\section{CONSIDERACIÓN DE CIRCUNSTANCIAS MODIFICATORIAS}

Puede suscitarse el problema de determinar en qué momento deben considerarse las circunstancias modificatorias concurrentes ${ }^{32}$. En el segundo inciso del artículo 351 la ley expresamente resuelve el punto, pues ordena tomar en cuenta "las circunstancias del caso" antes de efectuar el aumento de grados de pena ${ }^{33}$. En el primer inciso, en cambio, la ley nada dice. No obstante, según mi opinión, no puede efectuarse aquí una argumentación a contrario sensu, sino que lo que se indica en el inciso segundo también debe observarse en el primero, en aras de una interpretación armónica del precepto ${ }^{34}$. Carecería de sentido que en un caso (inciso primero) las circunstancias modificatorias se consideraran después de efectuado el aumento de pena y en el otro (inciso segundo), antes de dicho aumento ${ }^{35}$.

Parece avalar lo anterior el hecho de que, como lo he explicado, originalmente, el artículo 509 del Código de Procedimiento Penal contenía solo un inciso, el que ahora es el primero de aquella disposición y cuyo tenor es idéntico al del primer inciso del artículo 351 del Código Procesal Penal (salvo en lo relativo al número de grados en que debe aumentarse la pena). El inciso siguiente se agregó para ampliar el ámbito de aplicación de la regla de exasperación, no para alterarla, por lo que es posible afirmar que la introducción de la frase "con las circunstancias del caso" vino a explicitar lo que el inciso primero ordenaba en forma implícita, o sea, que el aumento debe hacerse después de graduar la pena según las circunstancias modificatorias concurrentes. La existencia de

${ }^{30}$ Así, Ortiz, L.; Arévalo, J., Las consecuencias jurídicas del delito, p. 339.

31 Para Solari, T.; Rodríguez, L., "Determinación de la pena en los casos de reiteración de delitos (ámbito de aplicación del artículo 509 del Código de Procedimiento Penal)”, pp. 262-264, las diversas infracciones pueden estimarse como un solo delito (y aplicárseles, en consecuencia, el primer inciso del artículo 351) cuando sean de la misma naturaleza (para determinar lo que debería atenderse a las descripciones típicas, concretamente, a la acción, las circunstancias y modos de ejecución recogidos en los tipos) y tengan, además, la misma pena.

32 Véase Oliver, G., “Aproximación a la unificación de penas”, p. 268.

33 Es lo que hace la Corte de Apelaciones de Temuco, en su sentencia de 19 de julio de 2006, dictada en causa rol $\mathrm{N}^{\circ} 721-2006$.

${ }^{34}$ Vivanco, J., "Manera y oportunidad de aumentar la pena en caso de reiteración de delitos de la misma especie. Comentario a sentencia de Corte Suprema de 9 de junio de 1970”, en Revista de Ciencias Penales,

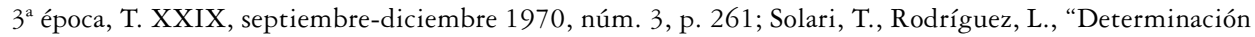
de la pena en los casos de reiteración de delitos (ámbito de aplicación del artículo 509 del Código de Procedimiento Penal)”, p. 265.

35 Couso, J., "Comentario previo a los artículos 74 y 75”, pp. 651-652. En contra, implícitamente, Ortiz, L.; Arévalo, J., Las consecuencias jurídicas del delito, p. 340. 
dicha frase en el inciso segundo y su ausencia en el inciso primero no significan, entonces, una diferente voluntad de la ley en cada caso ${ }^{36}$.

Sostener que en el inciso primero la ponderación de las circunstancias modificatorias debe hacerse después de efectuado el aumento de pena y en el inciso segundo, antes de exasperar la sanción, lleva al sinsentido de concluir que al extender la regla a quien incurre en una reiteración de delitos de la misma especie que por su naturaleza no pueden considerarse como un solo delito, el legislador quiso tratarle más benévolamente que a quien comete varios delitos de la misma especie que sí pueden estimarse como uno solo, a pesar de que, desde un punto de vista criminológico, en el primer caso, el delincuente podría parecer más peligroso, por su mayor variedad en la actividad delictiva ${ }^{37}$.

Por esto decía más arriba que carece de toda importancia práctica la determinación de qué inciso aplicar, el primero o el segundo, del citado artículo 351, cuestión que pasa a ser solamente de orden clasificatorio. Si en ambos casos se debe establecer primeramente la sanción que corresponde a cada uno de los delitos que integran la reiteración y considerar luego las circunstancias modificatorias concurrentes, para determinar como base del posterior aumento de uno o dos grados el marco del delito que resulte con pena más grave, o el de cualquiera de ellos si la pena es la misma, desde un punto de vista penológico, da lo mismo que se haga aplicación de un inciso o del otro ${ }^{38}$.

\section{Forma de hacer el aumento de PEna}

Establecido ya cómo determinar el marco penal del cual se debe partir para efectuar los aumentos de grado que ordena el artículo 351 del Código Procesal Penal, corresponde ahora examinar la manera en que tal exasperación debe realizarse. Según dicho precepto, la pena correspondiente a las diversas infracciones estimadas como un solo delito (inciso primero) o la señalada a aquella que, considerada aisladamente, tuviere asignada una pena mayor (inciso segundo) debe aumentarse en uno o dos grados. De ello se deduce que para que sea aplicable esta regla de punición, es necesario que la pena a ser agravada se encuentre en alguna de las escalas graduales de penas del artículo 59 del Código Penal $^{39}$. Por lo tanto, no podría aplicarse si dicha pena fuera, por ejemplo, de multa.

La cuestión relativa a la manera en que debe efectuarse el aumento es relevante no solo para la regla de punición de la reiteración de delitos de la misma especie, sino

${ }^{36}$ Así, Vivanco, J., "Manera y oportunidad de aumentar la pena en caso de reiteración de delitos de la misma especie. Comentario a sentencia de Corte Suprema de 9 de junio de 1970”, pp. 261-262.

37 Ídem, p. 262.

38 Así, Couso, J., “Comentario previo a los artículos 74 y 75”, pp. 652-653.

39 Similar, Matus, J.P., "Proposiciones respecto de las cuestiones no resueltas por la Ley N 20.084 en materia de acumulación y orden de cumplimiento de las penas", p. 537, quien, no obstante, exige que al menos uno de los delitos cometidos cumpla con este requisito. A mi juicio, no basta con eso, sino que es necesario que sea el marco del delito que resulte con pena más grave (o el de cualquiera de los cometidos si la pena es la misma) el que satisfaga dicha exigencia. 
para cada hipótesis en que el legislador permite u ordena aumentar la pena en uno o más grados sin explicitar la forma en que ello debe hacerse (verbigracia, en los artículos 290, 331, 345, 400 y 450 inciso segundo del Código Penal ${ }^{40}$ ). Pero en estos casos la dificultad se presenta, únicamente, cuando la pena a ser agravada se compone de dos o más grados, ya que cuando consta de un único grado, la forma de hacer el aumento (en un grado) parece sencilla: imponer el grado de pena inmediatamente superior.

Cuando se trata de un marco penal compuesto, las posibles formas de efectuar el aumento son, primordialmente, dos: a) desde el máximo, o sea, imponiendo el grado de pena inmediatamente superior al máximo del marco, con lo que la pena compuesta se transforma en un único grado (por ejemplo, el presidio mayor en su grado mínimo a medio, aumentado en un grado, se convertiría en presidio mayor en grado máximo); o b) en bloque, es decir, aumentando tanto el grado inferior como el superior del marco, caso en el que la pena sigue siendo compuesta (verbigracia, si se aumentara en un grado, la pena de presidio mayor en su grado mínimo a medio daría lugar al presidio mayor en su grado medio a máximo).

En la jurisprudencia se observan ambas formas de hacer el aumento de pena ${ }^{41}$. Algunas sentencias que lo efectúan desde el grado máximo del marco penal compuesto, argumentan que lo superior a un todo lo es en relación con el máximo de ese todo, y que el inciso cuarto del artículo 68 del Código Penal establecería la regla acerca de la forma en que se hacen los aumentos (imponer la pena inmediatamente superior en grado al máximo de los designados por la ley). Otros fallos que realizan un aumento "en bloque" sostienen que atendido que cada grado de una pena divisible constituye pena distinta (Art. $57 \mathrm{CP}$ ), el aumento de una pena compuesta por dos o más grados debe abarcar la integridad de los grados y no recaer solo sobre la pena más alta; que a partir de lo dispuesto en el inciso cuarto del citado artículo 68 corresponde realizar en esta materia una interpretación a contrario sensu, y que si un marco penal compuesto se aumentara desde el máximo, se convertiría en un solo grado de pena, lo que perjudicaría al condenado, porque según la regulación de los efectos de una pluralidad de atenuantes, cuando la pena señalada al delito es un grado de una divisible (Art. 67 inc. $4^{\circ} \mathrm{CP}$ ), se permite una rebaja de solo dos grados, mientras que si se trata de una pena compuesta por dos o más grados, se permite una rebaja de hasta tres grados (Art. 68 inc. $\left.3^{\circ} \mathrm{CP}\right)^{42}$.

${ }^{40}$ Los ejemplos relativos a los artículos 331 y 345 del Código Penal han sido extraídos de Matus, J.P., Van Weezel, A., “Artículos 50 a 73”, en Politoff, S., Ortiz, L. (dirs.), Matus, J.P. (coord.), Texto y comentario del Código Penal chileno, T. I, Libro Primero - Parte General, Editorial Jurídica de Chile, Santiago, 2002, p. 368, quienes señalan que los casos en que esto sucede son pocos.

${ }^{41}$ Aplican el aumento desde el grado máximo, entre otras sentencias, la de la Corte de Apelaciones de San Miguel, de 26 de marzo de 2012, dictada en causa rol No 155-2012, y la de la Corte de Apelaciones de Coyhaique, de 4 de junio de 2005, dictada en causa rol No 37-2005. Optan por un aumento "en bloque", entre otros fallos, los de la Corte Suprema, de 19 de abril de 2012, dictado en causa rol No 8784-2011; de la Corte de Apelaciones de San Miguel, de 13 de junio de 2011, dictado en causa rol No 369-2010, y de la Corte de Apelaciones de Santiago, de 7 de septiembre de 2010, dictado en causa rol No 1418-2010.

${ }^{42}$ Cfr. Novoa, E., Curso de Derecho Penal Chileno. Parte General, T. II, pp. 357-358. 
Con todo, también es posible encontrar algunas sentencias que efectúan el aumento del marco penal compuesto desde el mínimo, o sea, elevando solo su grado inferior (por ejemplo, el presidio mayor en su grado mínimo a medio, aumentado en un grado, se convertiría en presidio mayor en su grado medio $)^{43}$.

Teóricamente, una cuarta posibilidad consistiría en, manteniendo inalterado el límite inferior del marco penal compuesto, aumentar en uno o dos grados su límite superior (verbigracia, si se aumentara en un grado, la pena de presidio mayor en su grado mínimo a medio daría lugar al presidio mayor en su grado mínimo a máximo).

La doctrina, por su parte, en general, suele inclinarse por la forma de aumento que llamamos "en bloque" 44 .

Según mi opinión, reconociendo que el punto es discutible, parece preferible que el aumento que ordena el artículo 351 del Código Procesal Penal se realice a partir del grado máximo del marco penal. En primer lugar, porque así lo sugiere una interpretación sistemática que tome en cuenta los efectos que la ley asigna a la concurrencia de dos o más agravantes y ninguna atenuante cuando la pena de un delito consta de dos o más grados (Art. 68 inc. $\left.4^{\circ} \mathrm{CP}\right)^{45}$. Imaginemos que un delito tiene una pena de presidio menor en sus grados medio a máximo (por ejemplo, el robo por sorpresa, Art. 436 inc. $2^{\circ} \mathrm{CP}$ ) y que en su comisión concurren dos agravantes y ninguna atenuante. De acuerdo con el artículo 68 del Código Penal, en una situación como esta, el tribunal tendría dos posibilidades: a) aplicar el efecto que obligatoriamente se prevé para la concurrencia de una agravante, esto es, no imponer el grado mínimo (inc. $2^{\circ}$ ), caso en que el marco penal disponible sería el de presidio menor en su grado máximo, o bien, b) aplicar el efecto que facultativamente se contempla para la presencia de dos o más agravantes, es decir, imponer la pena inmediatamente superior en grado al máximo (inc. $4^{\circ}$ ), caso en que el marco disponible sería el de presidio mayor en su grado mínimo. En otras palabras, si a un robo por sorpresa le acompañan dos agravantes, el tribunal podría aplicar la pena de presidio menor en su grado máximo o la de presidio mayor en su grado mínimo.

Pues bien, si en una reiteración de dos o más robos por sorpresa el aumento de la pena ordenado por el artículo 351 del Código Procesal Penal se hiciera "en bloque”,

${ }^{43}$ En este sentido, pueden verse las sentencias de la Corte de Apelaciones de Valparaíso, de 26 de septiembre de 2011, dictada en causa rol No 976-2011; de la Corte de Apelaciones de Valdivia, de 15 de julio de 2011, dictada en causa rol No 226-2011, y de la Corte de Apelaciones de Santiago, de 17 de diciembre de 2010, dictada en causa rol No 2327-2010.

${ }^{44}$ Se declaran partidarios de esta forma de aumento, Novoa, E., Curso de Derecho Penal Chileno. Parte General, T. II, p. 358; Cury, E., Derecho Penal. Parte General, p. 762; Matus, J.P.; Van Weezel, A., "Artículos 50 a 73”, pp. 368-369; Garrido, M., Derecho Penal. Parte General, 2a edición, Editorial Jurídica de Chile, Santiago, 2005, T. I, p. 320. Optan, en cambio, por imponer el grado superior al máximo del marco penal, Pica, R., Reglas para la aplicación de las penas, 4a edición, Editorial Jurídica de Chile, Santiago, 1992, pp. 145, 162-163, 199-201, aludiendo a los aumentos de pena que ordenan los artículos 290, 331 y 400 del Código Penal, respectivamente; Correa, J.D., Aplicación práctica de las penas, Editorial Jurídica Aremi, Santiago, 2011, pp. 398 y 491, haciendo referencia a las agravaciones ordenadas por los artículos 331 y 400 del Código Penal, respectivamente.

${ }^{45}$ Una interpretación de esta clase, que lleva a la misma conclusión, realiza Cortés, J.L., Algunos aspectos de la reiteración de delitos de la misma especie, pp. 21-23. 
el marco penal resultante del aumento en un grado sería de presidio menor en grado máximo a presidio mayor en grado mínimo, un marco penal compuesto por exactamente los mismos grados que podría imponer el tribunal en la hipótesis de un solo robo por sorpresa acompañado de dos agravantes. Esto demuestra la incorrección de esta forma de aumentar la pena, ya que conduce al contrasentido de apreciar de la misma manera dos situaciones que, en su esencia, son valorativamente distintas: la de un delito (con dos agravantes) y la de dos o más delitos. El dato accidental de la pluralidad de agravantes no puede pasar por alto la evidente diferencia que existe a nivel de merecimiento y de necesidad de pena, entre la comisión de un solo delito y la de varios delitos. El aumento de la pena a partir del grado máximo del marco penal compuesto, en cambio, respeta esta diferencia valorativa.

Además, el incremento de pena "en bloque" presenta el problema de que distorsiona el sistema de la exasperación, al permitir la aplicación de una pena que ya estaba comprendida dentro del marco penal disponible antes de efectuar el aumento. Retomando el ejemplo de la reiteración de dos o más robos por sorpresa, si se aumentara de esta manera la pena en un grado, se llegaría a la de presidio menor en grado máximo a presidio mayor en su grado mínimo, dejando al tribunal la posibilidad de imponer uno u otro grado. Si decidiera aplicar presidio menor en su grado máximo, estaría imponiendo una pena que ya estaba incluida en el marco penal antes de aumentarlo, con lo que, en verdad, este no se habría exasperado y habría sido objeto solo de una forma de absorción agravada, como la que prevé el artículo 75 del Código Penal para una hipótesis muy distinta: la del concurso ideal de delitos ${ }^{46}$. Como afirma Cuerda Riezu, "rasgo característico de la exasperación es [...] sobrepasar el límite superior de la pena disponible" ${ }^{47}$. Aumentar la sanción desde el grado máximo de la pena compuesta, en cambio, se muestra compatible con el sistema de exasperación ${ }^{48}$.

Por esta misma razón, tampoco son aceptables las otras dos posibilidades expuestas más arriba acerca de la forma de realizar el aumento del marco penal compuesto: la que lo efectúa desde el mínimo y la que, manteniendo intacto el límite inferior, eleva el superior. Además, esta última posibilidad teórica presenta el problema, especialmente cuando se trata de marcos penales compuestos por más de dos grados, que se pretenden

${ }^{46}$ Explica la diferencia entre la agravación de pena que ordena la regla de la reiteración de delitos de la misma especie y la que impone el artículo 75 del Código Penal, Fontecilla, R., Concursos de delincuentes, de delitos y de leyes penales y sus principales problemas jurídicos, Editorial Jurídica de Chile, Santiago, 1956, p. 80, quien, al aludir al artículo 509 del Código de Procedimiento Penal (en rigor, solo a su primer inciso), pero con una argumentación igualmente aplicable al artículo 351 del Código Procesal Penal, afirma que "el aumento de pena, en este caso, excede del grado señalado por la ley; mientras que en el concurso ideal permanece dentro del grado, aplicándose la pena solo en su máximo”.

${ }^{47}$ Cuerda, A., Concurso de delitos y determinación de la pena, p. 116.

${ }^{48}$ Similar, Cortés, J.L., Algunos aspectos de la reiteración de delitos de la misma especie, p. 24, quien agrega, con razón, que la tesis del aumento "desde el máximo" de los marcos penales compuestos presenta la ventaja de que "supone tratar igual a aquel que se hace acreedor de un aumento de un marco originalmente integrado por un solo grado, que luego de efectuado el incremento, no podría acceder a una pena comprendida en el marco original". 
aumentar en dos grados, de que dan lugar a nuevos marcos penales demasiado amplios ${ }^{49}$ y difícilmente compatibles con el principio de taxatividad de la ley penal, incluso aceptando que en el señalamiento de las penas puede haber una mayor flexibilidad que en la descripción de la conducta punible, para permitir el logro de objetivos de prevención especial $^{50}$.

Los argumentos esgrimidos por los partidarios del aumento "en bloque" no parecen de recibo. En primer lugar, lo establecido en el artículo 57 del Código Penal no impide entender que cuando el artículo 351 del Código Procesal Penal ordena aumentar la pena, lo hace pensando en imponer una superior a toda ella y no solo a una de sus partes; de lo contrario, como lo he dicho, no se la estaría exasperando. En segundo término, nada sugiere que deba realizarse una interpretación a contrario sensu a partir de lo dispuesto en el inciso cuarto del artículo 68 del Código Penal, ya que también sería plausible sostener que dicha norma consagra de modo general la forma de efectuarse el aumento de las penas compuestas por dos o más grados; en todo caso, lo relevante es que una interpretación a contrario sensu conduce a un contrasentido valorativo, como también lo he explicado. Por último, no es cierto que al aumentarse un marco penal compuesto desde el grado máximo y convertirse en un solo grado de pena deba aplicarse el artículo 67 en vez del artículo 68 del Código Penal, porque esta argumentación olvida que las circunstancias modificatorias concurrentes deben considerarse antes de efectuarse el aumento, para determinar el marco penal que se usará como base de este, como lo he señalado; una vez exasperada la pena, tales circunstancias solo pueden servir para determinar la cuantía exacta de la sanción, según el artículo 69 del mismo Código.

Debo reconocer que la tesis que defiendo, al postular la supresión de todos los grados de pena de los marcos compuestos cuando son aumentados de acuerdo con el citado artículo 351 y su sustitución por el inmediatamente superior al grado máximo -cuando el aumento es de un grado- o por el siguiente -cuando el aumento es de dos grados-, podría producir un problema práctico derivado de la reducción de la posibilidad del imputado de acceder a algunos beneficios procesales o penales cuya admisibilidad depende, entre otras cosas, de la pena probable, solicitada o impuesta, como la suspensión condicional del procedimiento, el procedimiento abreviado y las penas sustitutivas. Sin embargo, dicho problema se ve notoriamente aminorado si se tiene presente que el inciso tercero del mencionado artículo 351 efectúa una remisión al artículo 74 del Código Penal, supeditada al hecho de que con ello se obtenga un tratamiento punitivo más benigno ${ }^{51}$, lo que a pesar de que la ley utiliza una fórmula verbal que permitiría pensar que ello, es facultativo (Podrá), es entendido, con razón, por la doctrina, como algo imperativo 52 .

${ }^{49}$ Así, Calderón, C., Algunos aspectos de las reglas de punición de la reiteración de delitos de la misma especie, Pontificia Universidad Católica de Valparaíso, Valparaíso, 2013, p. 34.

${ }^{50}$ Cfr. Zugaldía, J.M., Fundamentos de Derecho Penal, $3^{\text {a }}$ edición, Tirant lo Blanch, Valencia, 1993, p. 284.

${ }^{51}$ En este sentido, Cortés, J.L., Algunos aspectos de la reiteración de delitos de la misma especie, p. 26.

52 Por todos, Cury, E., Derecho Penal. Parte General, p. 661. 


\section{Comparación CON El Resultado de la APliCaCión DE LA REGLA DE ACUMULACIÓN ARITMÉTICA}

En otro orden de ideas, un sector de la doctrina sostiene que al efectuarse la comparación entre la regla del artículo 351 del Código Procesal Penal y la del artículo 74 del Código Penal para determinar cuál sanción resulta más benigna para el imputado, debería atenderse solo a consideraciones cuantitativas (no cualitativas), ya que el citado artículo 351 utiliza para ello la expresión pena menor (inc. $\left.3^{\circ}\right)^{53}$.

Sin embargo, a mi juicio, es perfectamente posible realizar una comparación no solo cuantitativa acerca de la duración temporal de las penas posibles de imponer, sino también cualitativa en relación con su gravedad, en la determinación de cuál es más favorable ${ }^{54}$. En otras palabras, estimo procedente efectuar las consideraciones que la teoría de la sucesión de leyes penales suele hacer para desentrañar cuál ley (la vigente al tiempo del hecho o la que entra en vigor con posterioridad) es más benigna. Desde un punto de vista teleológico, una comparación cualitativa de las penas (que acompañe a una cuantitativa) no puede entenderse excluida, porque esto implicaría la posibilidad de imponer sanciones de gravedad considerable (aunque de duración acotada) que constituyan una intervención penal excesiva para la entidad y el número de los delitos cometidos. Precisamente para evitar esto se creó la regla de punición de la reiteración de delitos de la misma especie. Además, el argumento literal que esgrime la tesis que critico no parece de recibo, ya que según el Diccionario de la Lengua Española de la Real Academia Española, la voz "menor" quiere decir, en su primera acepción, "inferior a otra cosa en cantidad, intensidad o calidad" "55, significado que coincide con el sentido natural y obvio del término, según su uso general. Esto demuestra que el campo semántico de dicho vocablo no solo permite utilizar consideraciones cuantitativas, sino también cualitativas.

\section{Aplicación conjunta de artículos 74 CP y 351 CPP}

Un sector de la doctrina afirma que no resulta posible aplicar conjuntamente, en un mismo juzgamiento, las reglas de punición de concursos de delitos de los artículos 351 del Código Procesal Penal y 74 del Código Penal, de modo que si entre los varios delitos objeto de condena hay algunos que son de la misma especie y otros que no lo son, solo sería aplicable, para todos, la regla de la acumulación aritmética del citado artículo 74. Tal aseveración se funda en un argumento literal: el mencionado artículo 74 , en su inciso primero, dispone que al delincuente se le impondrán "todas las penas correspondientes a las diversas infracciones" ${ }^{56}$, en tanto que el señalado artículo 351, en

53 Así, Matus, J.P., "Proposiciones respecto de las cuestiones no resueltas por la Ley $\mathrm{N}^{\circ} 20.084$ en materia de acumulación y orden de cumplimiento de las penas”, p. 538.

${ }^{54}$ Cfr. Oliver, G., “Aproximación a la unificación de penas”, p. 268.

55 El destacado en cursiva es mío.

${ }^{56}$ Las cursivas son mías. 
sus dos primeros incisos, también alude a las diversas infracciones, lo que evidenciaría el propósito de la ley de aplicar a todos los delitos objeto de una misma condena una u otra regla de punición ${ }^{57}$.

Según mi opinión, este argumento no resulta decisivo, porque bien podría sostenerse que las diversas infracciones a las que alude el citado artículo 351 no son todas las cometidas, sino únicamente las que son de la misma especie ${ }^{58}$, y correlativamente, que las diversas infracciones a las que se refiere el mencionado artículo 74 tampoco son todas las cometidas, sino solo las que no son de la misma especie. Además, no se advierte ninguna razón material que justifique una limitación como esta en la aplicación de aquel precepto ${ }^{59}$ y tampoco se trata de una restricción que se observe en la práctica de nuestros tribunales ${ }^{60}$. Por lo tanto, si en un mismo juicio se condenara a alguien por varios delitos, algunos de los cuales fueran de la misma especie y otros no, a los primeros les sería aplicable el artículo 351 del Código Procesal Penal y a los segundos, el artículo 74 del Código Penal.

\section{Reiteraciones de Delitos de la misma especie sujetas}

\section{A REGLAS ESPECIALES}

El artículo 351 del Código Procesal Penal contiene la regla general de punición de la reiteración de delitos de la misma especie. Existen ciertos casos especiales de reiteración de un mismo delito que se encuentran sometidos a reglas distintas. A examinar algunas de estas hipótesis se destinan las siguientes líneas.

\subsection{Reiteración de burtos contra una misma persona o contra distintas personas en un mismo lugar}

De acuerdo con el artículo 451 del Código Penal, en los casos de reiteración de hurtos, aunque se trate de faltas, a una misma persona, o a distintas personas en una misma casa, establecimiento de comercio, centro comercial, feria, recinto o lugar el tribunal calificará el ilícito y hará la regulación de la pena tomando por base el importe total de los objetos sustraídos, y la impondrá

${ }^{57}$ Así, Solari, T.; Rodríguez, L., "Determinación de la pena en los casos de reiteración de delitos (ámbito de aplicación del artículo 509 del Código de Procedimiento Penal)”, pp. 268-269, haciendo referencia al artículo 509 del Código de Procedimiento Penal, pero con una argumentación que también parece aplicable al artículo 351 del Código Procesal Penal.

${ }^{58}$ En este sentido, Couso, J., "Comentario previo a los artículos 74 y 75”, p. 653.

59 Ídem, p. 654 . Véase también Calderón, C., Algunos aspectos de las reglas de punición de la reiteración de delitos de la misma especie, pp. 30-31.

${ }^{60}$ Entre muchas otras sentencias en las que se ha hecho aplicación conjunta de los artículos 74 del Código Penal y 351 del Código Procesal Penal, pueden verse las de la Corte de Apelaciones de Santiago, de 22 de marzo de 2011, dictada en causa rol No 34-2011, y de la Corte de Apelaciones de Valparaíso, de 25 de febrero de 2011, dictada en causa rol No 25-2011. 
al delincuente en su grado superior. Su inciso segundo agrega que esta regla es sin perjuicio de lo dispuesto en el artículo 447.

Como se puede advertir, este precepto consagra una excepción a la regla de castigo de la reiteración de delitos de la misma especie contemplada en los artículos 351 y 397 del Código Procesal Penal, ya que si no existiera serían estas las disposiciones que deberían aplicarse en el supuesto de reiteración de hurtos que se describe.

Antiguamente se creía que había aquí una manifestación de la figura del delito continuado $^{61}$. Sin embargo, actualmente se sostiene, con razón, que no se trata de un único delito (continuado), sino de varios ${ }^{62}$. La propia disposición emplea la voz "reiteración", lo que supone una pluralidad delictiva ${ }^{63}$. No es entonces un delito continuado tratado con severidad (la consecuencia de considerar que el delito continuado es uno solo, es la de aplicarle la pena correspondiente al hecho único cometido ${ }^{64}$; el artículo 451 del Código Penal, en cambio, contempla una agravación), sino un concurso material de delitos tratado con benignidad ${ }^{65}$, probablemente por la estrecha conexión que existe entre las diversas acciones, lo que hace que se parezca a un delito continuado ${ }^{66}$. Si tuviera lugar un delito continuado de hurto, de aceptarse la aplicabilidad del delito continuado en el ordenamiento jurídico chileno, aun a falta de consagración legal expresa, no se aplicaría esta disposición, sino el artículo 446 del Código Penal.

A pesar de que se conoce esta regla con el nombre de "reiteración de hurtos", para que se aplique no basta con que se demuestre que ha habido un concurso material de hurtos, sino que se requiere, además, como el precepto lo exige, que se acredite que los diversos delitos se han cometido contra una misma persona, cualquiera hayan sido sus lugares de ejecución, o contra distintas personas en un mismo lugar. En el delito de robo con fuerza en las cosas, a la voz "lugar" suele darse un sentido muy preciso: un espacio delimitado y cerrado ${ }^{67}$. En materia de hurto, en cambio, no existen razones

${ }^{61}$ Así, Fontecilla, R., Concursos de delincuentes, de delitos y de leyes penales y sus principales problemas jurídicos, p. 70; Pica, R., Reglas para la aplicación de las penas, p. 223; Del Río, R., Derecho Penal, Editorial Nascimento, Santiago, 1935, T. III, p. 456; Labatut, G., Derecho Penal, $7^{\text {a }}$ edición actualizada por Julio Zenteno Vargas, Editorial Jurídica de Chile, Santiago, 2000, T. II, p. 215.

${ }^{62}$ Garrido, M., Derecho Penal. Parte Especial, 4a edición, Editorial Jurídica de Chile, Santiago, 2008, T. IV, p. 269.

${ }^{63}$ Ya se pronunciaban en este sentido, Cury, E., "El delito continuado", en Revista de Ciencias Penales, T. XVIII, 1959, p. 208; Novoa, E., "El delito continuado en Chile: un fetiche jurídico", en Revista de Ciencias Penales, T. XXIII, 1964, p. 148.

${ }^{64}$ Cfr. Politoff, S.; Matus, J.P.; Ramírez, M.C., Lecciones de Derecho Penal Chileno. Parte General, p. 453. Excepcionalmente, Cury, E., Derecho Penal. Parte General, p. 658, postula la aplicación al delito continuado de la regla de penalidad del concurso medial (Art. 75 CP).

65 Así lo confirman las sentencias de la Corte de Apelaciones de Concepción, de 6 de julio de 2012, dictada en causa rol No 264-2012, y de la Corte de Apelaciones de Santiago, de 29 de mayo de 2006, dictada en causa rol $\mathrm{N}^{\circ} 765-2006$.

${ }^{66}$ Etcheberry, A., Derecho Penal. Parte General, T. II, pp. 113-114.

${ }^{67}$ Así, De la Fuente, F., "Los lugares de comisión del delito de robo con fuerza en las cosas: una clasificación bipartita”, en Rodríguez, L. (coord.), Delito, pena y proceso. Libro homenaje a la memoria del profesor Tito Solari Peralta, Editorial Jurídica de Chile, Santiago, 2008, p. 419. 
para dar a este vocablo un alcance tan restringido, por lo que puede entenderse como cualquier espacio, se encuentre delimitado y cerrado o no ${ }^{68}$. Lo más frecuente será que los diversos delitos se cometan en espacios delimitados y cerrados, pero puede que no sea así. De hecho, la propia disposición menciona la voz "feria", la que, como es sabido, muchas veces no ocupa un espacio cerrado.

Por otra parte, la agravación que la regla contempla, en virtud de los términos utilizados por el legislador para establecerla, resulta aplicable en pocos casos. Ello es así, porque tras ordenar que para determinar la sanción se tome por base el importe total de los objetos sustraídos, la disposición no obliga a aumentar la pena en un grado, sino a imponer la correspondiente "en su grado superior". Como se comprenderá, para que esto último pueda hacerse es necesario que el marco penal que corresponda a la sumatoria del valor de las cosas hurtadas sea compuesto por dos o más grados ${ }^{69}$. De los cinco marcos de pena que existen para el hurto, solo dos cumplen este requisito: el previsto en el artículo $446 \mathrm{~N}^{\circ} 1$ del Código Penal (presidio menor en sus grados medio a máximo), que será aplicable cuando la suma de los valores exceda de cuarenta (y no pase de cuatrocientas) unidades tributarias mensuales, y el contemplado en el artículo 494 bis del mismo Código (prisión en su grado mínimo a medio), que será aplicable cuando dicha sumatoria no exceda de media unidad tributaria mensual. En los restantes casos, esto es, cuando la suma total excede de media unidad tributaria mensual y no pasa de cuatro unidades tributarias mensuales (Art. $446 \mathrm{~N}^{\circ} 3 \mathrm{CP}$ ), o si excede de cuatro y no pasa de cuarenta unidades tributarias mensuales (Art. $446 \mathrm{~N}^{\circ} 2 \mathrm{CP}$ ), o si excede de cuatrocientas unidades tributarias mensuales (Art. 446 inc. final CP), la agravación no resulta aplicable, porque la sanción privativa de libertad consiste en un único grado, con lo que la pena a imponer será idéntica a la que correspondería si se tratara de un delito continuado ${ }^{70}$.

En todo caso, lo recién señalado no necesariamente significa que en la hipótesis de reiteración de hurtos en que se pone el artículo 451 del Código Penal no exista una forma de exasperación de la sanción, sino una de absorción agravada. La agravación consistente en imponer la pena en su grado superior no recae sobre la sanción del hurto más grave, sino sobre la correspondiente al valor total de lo sustraído en los diversos delitos. Al sumar previamente el importe de los objetos sustraídos en los diferentes hurtos, es muy probable que se llegue a un marco penal superior al que corresponda al delito más grave. Así sucedería, por ejemplo, si un sujeto en cinco ocasiones y en un mismo lugar cometiera un hurto de objetos de un valor individual de una unidad tributaria mensual. La pena privativa de libertad de cada delito sería de presidio menor en su grado mínimo

${ }^{68}$ En contra, Politoff, S.; Matus, J.P.; Ramírez, M. C, Lecciones de Derecho Penal Chileno. Parte Especial, p. 313 .

${ }^{69}$ Garrido, M., Derecho Penal. Parte Especial, T. IV, p. 269; Etcheberry, A., Derecho Penal. Parte Especial, $3^{\text {a }}$ edición, Editorial Jurídica de Chile, Santiago, 1998, T. III, p. 362. En contra, implícitamente, Muñoz, H., "Contribución al estudio de la teoría de los concursos de delitos", p. 350, quien al contraponer el artículo 451 del Código Penal con el artículo 509 del Código de Procedimiento Penal, afirma que en aquel caso "la pena es menor, pues solo se aumentará en un grado, y no podrá aumentarse en dos o tres grados" (las cursivas son mías).

${ }^{70}$ Politoff, S.; Matus, J.P.; Ramírez, M.C., Lecciones de Derecho Penal Chileno. Parte Especial, p. 312. 
(Art. $446 \mathrm{~N}^{\circ} 3 \mathrm{CP}$ ), pero la correspondiente al valor total de lo sustraído sería de presidio menor en su grado medio (Art. $446 \mathrm{~N}^{\circ} 2 \mathrm{CP}$ ).

A pesar de que el citado artículo 451 no expresa nada sobre el particular, pienso que si su aplicación condujera a una sanción cuya cuantía supere a la suma de las penas que correspondiera imponer según la regla de acumulación aritmética del artículo 74 del Código Penal, debería hacerse aplicación de este último precepto, por contener la regla general en materia de concursos de delitos. Carecería de sentido que por aplicar un precepto creado para tratar con mayor benignidad un caso especial de concurso material de delitos se impusiera una pena que resulte superior a la aplicable de acuerdo con la regla general.

\subsection{Reiteración de receptaciones}

Según lo que dispone el artículo 456 bis A del Código Penal, "el que conociendo su origen o no pudiendo menos que conocerlo, tenga en su poder, a cualquier título, especies hurtadas, robadas u objeto de abigeato, de receptación o de apropiación indebida del artículo 470, número $1^{\circ}$, las transporte, compre, venda, transforme o comercialice en cualquier forma, aun cuando ya hubiese dispuesto de ellas, sufrirá la pena de presidio menor en cualquiera de sus grados y multa de cinco a cien unidades tributarias mensuales" (inciso primero). Agrega su inciso segundo que "para la determinación de la pena aplicable el tribunal tendrá especialmente en cuenta el valor de las especies, así como la gravedad del delito en que se obtuvieron, si este era conocido por el autor". Añade el precepto que "cuando el objeto de la receptación sean vehículos motorizados o cosas que forman parte de redes de suministro de servicios públicos o domiciliarios, tales como electricidad, gas, agua, alcantarillado, colectores de aguas lluvia o telefonía, se impondrá la pena de presidio menor en su grado máximo y multa de cinco a veinte unidades tributarias mensuales. La sentencia condenatoria por delitos de este inciso dispondrá el comiso de los instrumentos, herramientas o medios empleados para cometerlos o para transformar o transportar los elementos sustraídos. Si dichos elementos son almacenados, ocultados o transformados en algún establecimiento de comercio con conocimiento del dueño o administrador, se podrá decretar, además, la clausura definitiva de dicho establecimiento, oficiándose a la autoridad competente" (inciso tercero). Según su inciso cuarto, que es el relevante en esta materia, se impondrá el grado máximo de la pena establecida en el inciso primero, cuando el autor haya incurrido en reiteración de esos hechos o sea reincidente en ellos. En los casos de reiteración o reincidencia en la receptación de los objetos señalados en el inciso precedente, se aplicará la pena privativa de libertad allí establecida, aumentada en un $\operatorname{grado}^{71}$. Según su inciso final, "tratándose del delito de abigeato la multa establecida en el inciso primero será de setenta y cinco a cien unidades tributarias mensuales y el juez podrá disponer la clausura definitiva del establecimiento”.

\footnotetext{
${ }^{71}$ El destacado en cursiva es mío.
} 
Como puede advertirse, esta disposición consagra otra excepción a la regla de punición de la reiteración de delitos de la misma especie del artículo 351 del Código Procesal Penal ${ }^{72}$. Se trata de una hipótesis de reiteración de receptaciones que tiene una forma especial de castigo, la que a veces se traduce en una absorción agravada y en otras ocasiones da lugar a una exasperación de la pena. Lo primero sucede cuando se trata de una reiteración de receptaciones que no recaen sobre vehículos motorizados o cosas que forman parte de redes de suministro de servicios públicos o domiciliarios, caso en el que se agrava la pena de presidio menor en cualquiera de sus grados y corresponde imponer la de presidio menor en su grado máximo; lo segundo ocurre cuando se trata de una reiteración de receptaciones que sí recaen sobre alguno de dichos objetos, situación en la que se aumenta en un grado la pena de presidio menor en su grado máximo y corresponde aplicar la de presidio mayor en su grado mínimo.

\section{BIBLIOGRAFÍA}

Bullemore, V.; Mackinnon, J., Curso de Derecho Penal, tomo II, Teoría del delito, $2^{a}$ edición, LexisNexis, Santiago, 2007.

Bustos, J.; Hormazábal, H., Lecciones de Derecho Penal Chileno, adaptadas por José Ángel Fernández Cruz, volumen I, Librotecnia, Santiago, 2012.

Calderón, C., Algunos aspectos de las reglas de punición de la reiteración de delitos de la misma especie, Pontificia Universidad Católica de Valparaíso, Valparaíso, 2013.

Correa, A., "Ochenta y cuatro años de presidio", en Revista Forense Chilena, núm. 4, 1888.

Correa, J.D., Aplicación práctica de las penas, Editorial Jurídica Aremi, Santiago, 2011.

Cortés, J.L., Algunos aspectos de la reiteración de delitos de la misma especie, Seminario de titulación Magíster en Derecho Penal y Ciencias Penales, Pontificia Universidad Católica de Valparaíso, Valparaíso, 2012.

Couso, J., "Comentario previo a los arts. 74 y 75”, en Couso, J., Hernández, H. (dirs.), Código Penal Comentado. Parte General. Doctrina y Jurisprudencia, Abeledo Perrot LegalPublishing Chile, Santiago, 2011.

Cuerda, A., Concurso de delitos y determinación de la pena, Tecnos, Madrid, 1992.

Cury, E., Derecho Penal. Parte General, $10^{\mathrm{a}}$ edición, Ediciones Universidad Católica de Chile, Santiago, 2011.

Cury, E., "El delito continuado", en Revista de Ciencias Penales, tomo XVIII, 1959.

De la Fuente, F., "Los lugares de comisión del delito de robo con fuerza en las cosas: una clasificación bipartita”, en Rodríguez Collao, Luis (coord.), Delito, pena y proceso. Libro homenaje a la memoria del profesor Tito Solari Peralta, Editorial Jurídica de Chile, Santiago, 2008.

Del Río, R., Derecho Penal, tomo III, Editorial Nascimento, Santiago, 1935.

Etcheberry, A., Derecho Penal. Parte General, tomo II, $3^{a}$ edición, Editorial Jurídica de Chile, Santiago, 1998.

${ }^{72}$ Le reconoce el carácter de regla especial de penalidad en materia de reiteración de delitos de la misma especie, la sentencia de la Corte de Apelaciones de Valparaíso, de 8 de agosto de 2006, dictada en causa rol No $840-2006$. 
Etcheberry, A., Derecho Penal. Parte Especial, tomo III, $3^{a}$ edición, Editorial Jurídica de Chile, Santiago, 1998.

Feliú, D., "De la acumulación de los delitos según nuestro Código Penal”, en Revista Forense Chilena, núm. 6, 1890.

Fontecilla, R., Concursos de delincuentes, de delitos y de leyes penales y sus principales problemas jurídicos, Editorial Jurídica de Chile, Santiago, 1956.

Fuensalida, A., Concordancias y comentarios del Código Penal chileno, tomo I, Lima, 1883.

Garrido, M., Derecho Penal. Parte General, tomo II, $2^{\text {a }}$ edición, Editorial Jurídica de Chile, Santiago, 2001.

Garrido, M., Derecho Penal. Parte General, tomo I, $2^{\mathrm{a}}$ edición, Editorial Jurídica de Chile, Santiago, 2005.

Garrido, M., Derecho Penal. Parte Especial, tomo IV, $4^{a}$ edición, Editorial Jurídica de Chile, Santiago, 2008.

Jescheck, H., Tratado de Derecho Penal. Parte General, traducción de la $4^{a}$ edición alemana de José Luis Manzanares Samaniego, Comares, Granada, 1993.

Labatut, G., Derecho Penal, tomo I, $9^{a}$ edición actualizada por Julio Zenteno Vargas, Editorial Jurídica de Chile, Santiago, 2000.

Labatut, G., Derecho Penal, tomo II, $7^{\text {a }}$ edición actualizada por Julio Zenteno Vargas, Editorial Jurídica de Chile, Santiago, 2000.

Latorre, E. ET AL., "Ciento veintitrés años cuarenta y un días de presidio", en Revista Forense Chilena, núm. 13, 1899.

Lazo, S., Código de Procedimiento Penal. Orígenes, concordancias, jurisprudencia, Poblete Cruzat Hnos. Editores, Santiago, 1916.

MaÑalich, J.P., “¿Discrecionalidad judicial en la determinación de la pena en caso de concurrencia de circunstancias atenuantes de la responsabilidad penal?”, en Informes en Derecho. Doctrina Procesal Penal 2009, No 7, octubre 2010.

Matus, J.P., "Proposiciones respecto de las cuestiones no resueltas por la Ley No 20.084 en materia de acumulación y orden de cumplimiento de las penas", en Ius et Praxis, No 2, 2008.

Matus, J.P.; Van Weezel, A., “Artículos 50 a 73”, en Politoff, S., Ortiz, L. (dirs.), Matus Acuña, Jean Pierre (coord.), Texto y comentario del Código Penal chileno, tomo I, Libro Primero - Parte General, Editorial Jurídica de Chile, Santiago, 2002.

Mera, J., Hurto y robo, LexisNexis, Santiago, 1995.

Mir, S., Derecho Penal. Parte General, 7ª edición, B de F, Montevideo - Buenos Aires, 2004.

MuÑoz, H., "Contribución al estudio de la teoría de los concursos de delitos", en Revista Chilena de Derecho, Pontificia Universidad Católica de Chile, vol. 13, núm. 2, 1986.

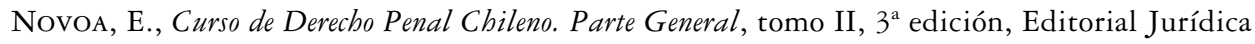
de Chile, Santiago, 2005.

Novoa, E., "El delito continuado en Chile: un fetiche jurídico", en Revista de Ciencias Penales, tomo XXIII, 1964.

Oliver, G., “Aproximación a la unificación de penas”, en Política Criminal, Vol. 7, N 14, diciembre 2012.

Oliver, G., Delitos contra la propiedad, Thomson Reuters LegalPublishing, Santiago, 2013.

Ortiz, P., Curso breve de Derecho Penal (común y militar), Imprenta de Carabineros de Chile, Santiago, 1947.

Ortiz, L., Arévalo, J., Las consecuencias jurídicas del delito, Editorial Jurídica de Chile, Santiago, 2013.

PICA, R., Reglas para la aplicación de las penas, 4ª edición, Editorial Jurídica de Chile, Santiago, 1992. 
Politoff, S.; Matus, J.P.; Ramírez, M.C., Lecciones de Derecho Penal Chileno. Parte Especial, $2^{\text {a }}$ edición, Editorial Jurídica de Chile, Santiago, 2004, reimpresión 2012.

Politoff, S.; Matus, J.P.; Ramírez, M.C., Lecciones de Derecho Penal Chileno. Parte General, $2^{a}$ edición, Editorial Jurídica de Chile, Santiago, 2004, reimpresión 2008.

Rodríguez, L.; Oliver, G., "Aplicabilidad de la figura del delito continuado en los delitos sexuales. Comentario a un fallo", en Revista de Derecho, Universidad Católica del Norte, $\mathrm{N}^{\circ} 1$, año 16, 2009.

Roxin, C., Derecho Penal. Parte General, tomo I, traducción de la $2^{\text {a }}$ edición alemana de DiegoManuel Luzón Peña, Miguel Díaz y García Conlledo y Javier de Vicente Remesal, Civitas, Madrid, 1997, reimpresión 1999.

SAnz, A.J., El concurso de delitos. Aspectos de política legislativa, Universidad de Valladolid, Valladolid, 1986.

Solari, T., Rodríguez, L., "Determinación de la pena en los casos de reiteración de delitos (ámbito de aplicación del art. 509 del Código de Procedimiento Penal)", en Revista de Derecho, Universidad Católica de Valparaíso, Vol. III, 1979.

Vivanco, J., "Manera y oportunidad de aumentar la pena en caso de reiteración de delitos de la misma especie. Comentario a sentencia de Corte Suprema de 9 de junio de 1970", en Revista de Ciencias Penales, $3^{\mathrm{a}}$ época, tomo XXIX, septiembre-diciembre 1970, $\mathrm{N}^{\circ} 3$.

Zugaldía, J.M., Fundamentos de Derecho Penal, $3^{\mathrm{a}}$ edición, Tirant lo Blanch, Valencia, 1993. 